\title{
Drug-eluting Embolic Bead
}

National Cancer Institute

\section{Source}

National Cancer Institute. Drug-eluting Embolic Bead. NCI Thesaurus. Code C97232.

An embolic bead that, in addition to blocking blood flow, also releases a

chemotherapeutic drug. 